\title{
ESTIMATION OF THE DYNAMIC PROPERTIES OF EPOXY GLASS FABRIC COMPOSITES WITH NATURAL RUBBER PARTICLE INCLUSIONS
}

\author{
H. Ravi Sankar ${ }^{1}$, R.R. Srikant ${ }^{1}$, P. Vamsi Krishna ${ }^{1}$, V. Bhujanga Rao ${ }^{2}$ and \\ P. Bangaru Babu ${ }^{3}$ \\ ${ }^{1}$ Dept. of Mechanical Engineering, GITAM University, Visakhapatnam, India. \\ ${ }^{2}$ Defence Research and Development Organisation, New Delhi, India. \\ ${ }^{3}$ Dept. of Mechanical Engineering, NIT Warangal, India. \\ Email: ravigitam.hota@gmail.com
}

\begin{abstract}
Conventional materials are being replaced in the field of engineering by composite materials, due to their tailorable properties and high specific properties. These materials are extensively used in structural applications. Damping is one of the important properties of the materials used in structures, and needs to be enhanced in order to reduce structural vibrations. In the present work, the improvement of the material damping of glass fabric epoxy composites with particle rubber inclusions is studied. The effect of particle size on the damping and stiffness parameters at different frequencies and temperatures is studied experimentally. Considerable enhancement in damping without significant reduction in stiffness is observed at lower particle sizes. The damping property in both bending and shear modes is more with $0.254 \mathrm{~mm}$ rubber particle inclusions among the selected sizes. A lower reduction in stiffness is observed with the inclusion of lower particle sizes $(0.254 \mathrm{~mm}$ and $0.09 \mathrm{~mm})$ when compared with higher particle sizes. An ANN-based prediction model is developed to predict these properties for a given frequency/temperature and particle size. The predicted values are very close to the experimental values with an maximum error of $5 \%$.
\end{abstract}

Keywords: Composites; damping enhancement; artificial neural networks.

\section{INTRODUCTION}

In the contemporary world, several conventional materials are being replaced by composites due to their several properties. Composites are finding application in many fields, from household articles to aircraft components (Ibrahim et al., 2012; Bachtiar et al., 2010; Adebisi et al., 2011; Saadatmanesh et al., 1994). In aircraft and other such applications, energy dissipation by mechanical damping is of considerable importance for reducing vibrations (Crandall, 1970). Damping in the structures is attained by either active methods or passive methods (Trindade et al., 2002). The use of sensors and actuators in active damping increases the system complexity and reduces the reliability. Passive damping is an inherent property of the system with less complexity and higher reliability (Trindade et al., 2002). The improvement in passive damping of structures has been achieved by various researchers through surface attachments (Hardinnawirda and Aisha, I. 2012; Mantena et al., 1991), co-cured viscoelastic layers (Rotz and Barrett, 1991) and fibre-coating techniques (Finegan and Gibson, 1997). Viscoelastic tapes were sandwiched between the base structure and a constrained layer for damping enhancement (Mantena et al., 1991). Though an improvement in damping is observed, the weight of the structure is increased due to the constrained layer. Rotz and Barrett 
(1991) designed composites with required damping using co-cured viscoelastic layers. Delamination at the interface is a major drawback with co-cured layers (Finegan and Gibson, 1997). Though the toughness and damping are two distinct properties, both involve the energy release phenomenon. Rubber particles were included in polymers (Collyer, 1994) to improve fracture toughness, but studies on damping with particle rubber inclusions are limited. A composite sound absorber is fabricated using recycled rubber particles with good attenuation properties to dampen the sound (Hong et al., 2004). Enhancement of structural damping with natural rubber particle inclusions and the effect of their size on modal damping ratios were studied using vibration tests (Ravi Sankar et al., 2010; Jeffrey et al., 2011). Composites with polypropylene and silicon rubber with Wollastonite as the fibrous filler in different proportions was fabricated to study its effect on mechanical properties following to the addition of silicon rubber (Bhaskar and Sharief, 2012; Umar et al., 2012; Upinder et al., 2009). Also short glass fibre (SGF) reinforced poly propylene composite was toughened with styrene-ethylene butylene styrene (SEBS) elastomers (Tjong et al., 2002).

Though damping is enhanced through CLD, co-cured layers and fibre coating methods a considerable increase in weight, delaminations at interleaved co-cured layers, and significant reduction in stiffness are the drawbacks of each of the cases respectively. Work reporting an improvement in the toughness of polymers using particle elastomers and resin modifications is limited to studies on toughness alone, but very few on damping even though both involve the process of energy dissipation. Damping enhancement through the addition of rubber particles though effective, the studies are confined to structural damping, depends on the shape and size of the structures and boundary conditions (Ravi Sankar et al., 2010). It requires a huge quantum of experimentation to decide upon the optimal choice of particle size. Hence there is a need to characterise the material damping (loss factor, Tan $\delta$ ) and dynamic stiffness (storage modulus, E') which is an inherent property of the material. DMA is a tool to characterise these properties. Tan $\delta$ and E' are complimentary to each other, and an optimal decision to strike a break-even is crucial. In this context, the aid of Artificial Neural Networks (ANN) may be sought.

The application of ANN for the mapping of the system and obtaining various outputs in the field of composites has gained momentum (Bose and Liang, 1998; Sapuan and Mujtaba, 2010; Zhang and Friedrich, 2003). The use of ANN in predicting different parameters in composites is well demonstrated by various researchers. Pidaparti and Palakal (1993) were among the first to use ANN as a constitutive model for composites. ANN was used to predict the fatigue strength of composites (Aymerich and Serra, 1998; Lee et al., 1998). A Back Propagation Neural Network (BPNN) was used to predict the fatigue failure of a glass fibre/epoxy laminate with a range of fibre orientation angles under various loading conditions (Al-Assaf and EI Kadi, 2001; Mathur et al., 2007). The results obtained were comparable with other prediction methods. The error between the experimental and predicted results was found to be less than $5 \%$ in most cases. However, in some cases the error was up to $28 \%$. ANN was applied to predict the mechanical and wear properties of short-fibre reinforced polyamide (PA) composites (Jiang et al., 2008). The predictions reported remarkable accuracy with the experimental results. Though BPNN is widely used, it suffers from major set-backs like local minima, poor convergence, etc. As an alternative, a Radial Basis Function (RBF) is used. A study of free vibration in symmetric composite plates based on a collocation by radial basis functions and pseudo spectral methods was presented and produced highly accurate results (Ferreira and Fasshauer, 2007). Both 
BPNN and RBF techniques were used to study the impact from components and process conditions on the properties of $\mathrm{Pb}-\mathrm{Al}$ composite materials ( $\mathrm{Zhu}$ et al., 2010). The predicted values were compared with experimental data and the RBF results were claimed to be the best. From the above literature, it can be concluded that ANN can be effectively used in composite materials research. Though BPNN is widely used, it suffers from major limitations and RBF is proven to be a better choice.

In the present work, the damping related parameters Tan $\delta$ and E' of particle rubber included in an epoxy glass fabric composite are evaluated in flexure and shear modes at different frequencies and in flexure at different temperatures using DMA. The RBF network is used for the prediction of the dynamic characteristics (Tan $\delta$ and E') of the composites. The estimated dynamic properties are used for building two RBF models to predict Tan $\delta$ and E' under two different scenarios, viz. in three-point bending and in shear, at various frequencies and in three-point bending with a temperature sweep.

\section{EXPERIMENTATION}

\section{Sample Fabrication}

Glass fabric epoxy composites with and without rubber particle inclusions are fabricated as per the required standards for DMA testing. Glass fabric epoxy composites of size $300 \mathrm{~mm} \times 180 \mathrm{~mm} \times 4 \mathrm{~mm}$ (die dimensions) are fabricated with and without natural particle rubber inclusions using a hand layup technique, from which the samples for DMA testing are cut. Natural rubber particles are segregated into four different particle sizes: $0.9 \mathrm{~mm}, 0.45 \mathrm{~mm}, 0.254 \mathrm{~mm}$ and $0.09 \mathrm{~mm}$. The segregated rubber particles of specific size are mechanically mixed in Lapox ${ }^{\circledR} 12$ epoxy resin followed by sonication for an hour in a sonicator for dispersing the particles uniformly in the resin. The weight of the particle rubber inclusions is $10 \%$ of the total weight of the composite (inclusions + resin + fibre). Before applying the rubber particle filled epoxy resin to the glass fibres, a hardener (Lapox ${ }^{\circledR} \mathrm{K} 6$ ) is mixed in the proportion 1:0.1 by weight. The mixture is added to glass fabric mats. A PVA mould releasing agent is applied to the mould before the laying up process for the easy removal of the fabricated composite plates. Serrated rollers are used to compact the material against the mould and to remove entrapped air, if any. The plates in the die are processed in press at room temperature under a pressure of $200 \mathrm{Kpa}$ for $24 \mathrm{hr}$ and then removed. The edges of the produced composite plates are finished with emery paper. In all the specimens the nominal content of glass fibre in the composite is set at $40 \%$ by weight, and the remaining $60 \%$ is resin, which is evaluated by burn out tests as per the ASTM standard (ASTM D2584-08, 2008). From the fabricated plates, rectangular samples of size $60 \mathrm{~mm} \times 10 \mathrm{~mm} \times 4 \mathrm{~mm}$ for three-point bending and $10 \mathrm{~mm} \times 10 \mathrm{~mm} \times 4 \mathrm{~mm}$ for shear are cut for testing in DMA Q800. 


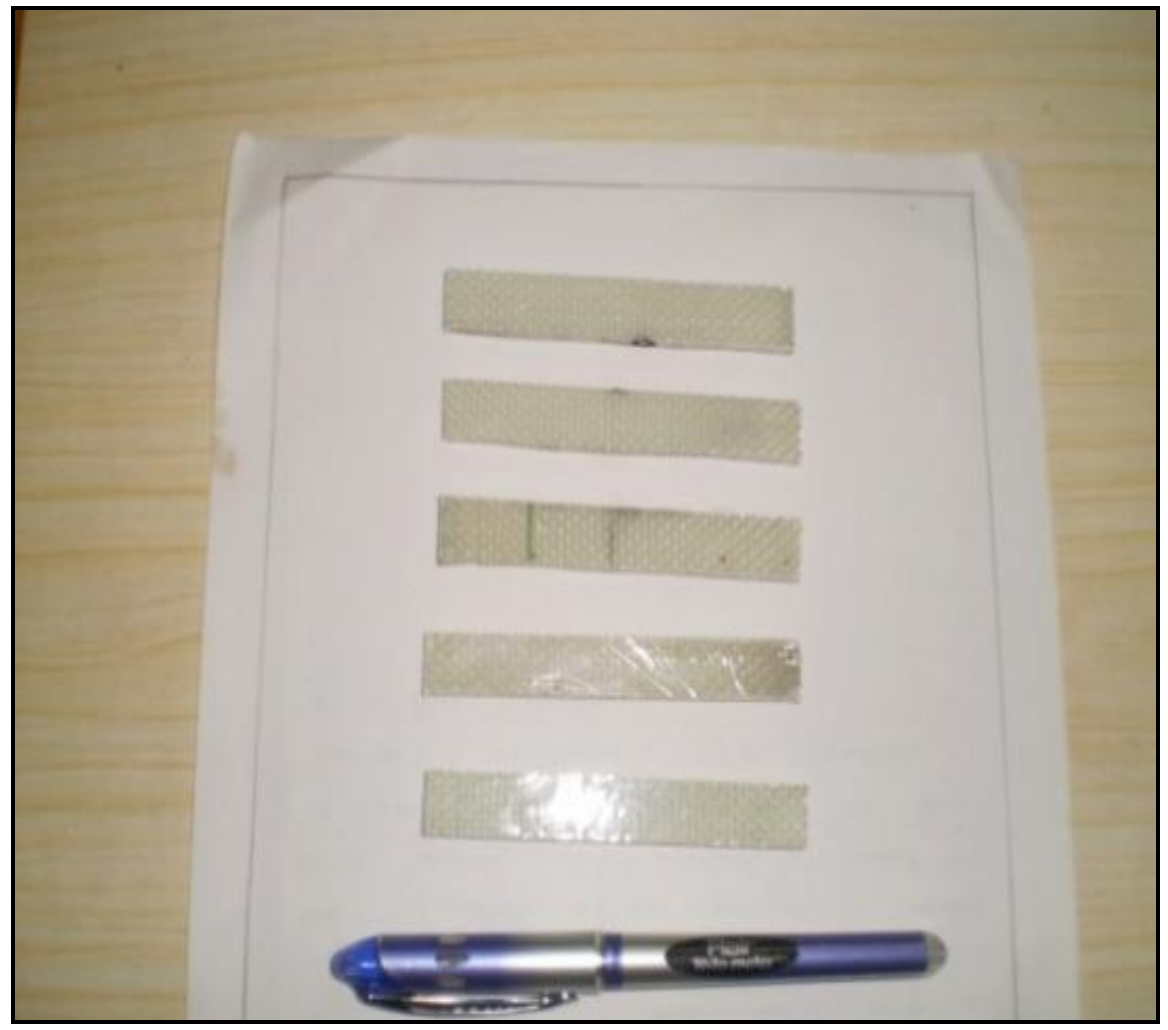

Figure 1. DMA samples for three-point bending

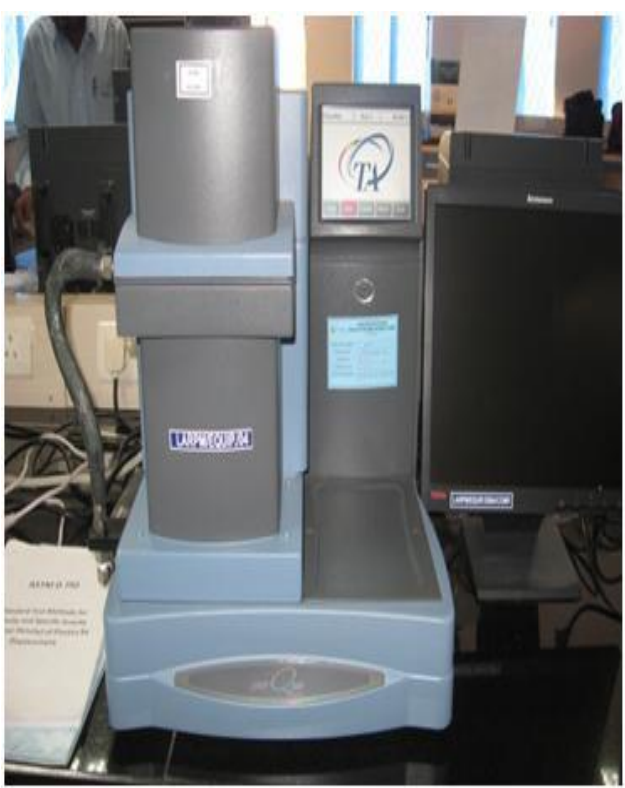

(a)

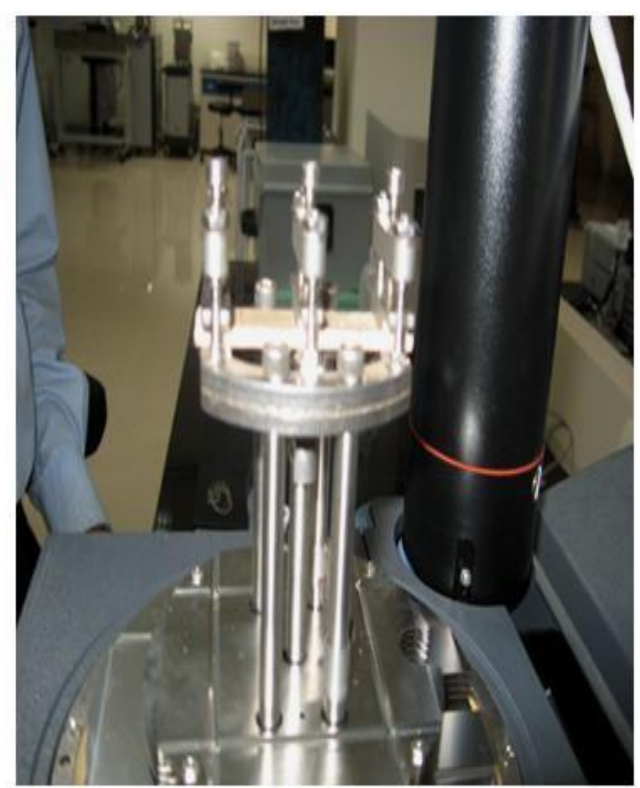

(b)

Figure 2. (a) DMA (b) specimen in DMA

\section{Scanning Electron Microscopy}

The properties of natural rubber particles included in composites strongly depend on the dispersion of the rubber particles in the matrix. To observe the dispersiblity of natural 
rubber particles in epoxy resin, cross-sections were examined by a Zeisis EVO MA15 scanning electron microscope (SEM) with an acceleration voltage of $10 \mathrm{KV}$. Samples are sputter coated with gold to make them conductive prior to SEM observations.

\section{DMA Studies}

The dynamic properties E' and Tan $\delta$ in three-point bending and in shear are evaluated with frequency sweep at room temperature and in three-point bending at $10 \mathrm{~Hz}$ with a temperature sweep. For temperature dependent properties, the samples are heated to $180^{\circ} \mathrm{C}$ in the case of the neat composite and up to $120^{\circ} \mathrm{C}$ in the case of rubbercontaining composite at a heating rate of $1^{0} \mathrm{C} / \mathrm{min}$.

\section{RESULTS AND DISCUSSION}

\section{SEM Studies}

The morphology of the cross-section of natural rubber-filled epoxy glass fibre composites is examined using SEM in order to examine the distribution of rubber particles in the composite. Figure 3 shows SEM images of the cross-section of glass epoxy composite specimen with rubber particle inclusions. It is observed that the rubber particles are well distributed in the matrix. The uniform dispersion of the rubber particles lead to ascertaining the dynamic properties Tan $\delta$ and E'.

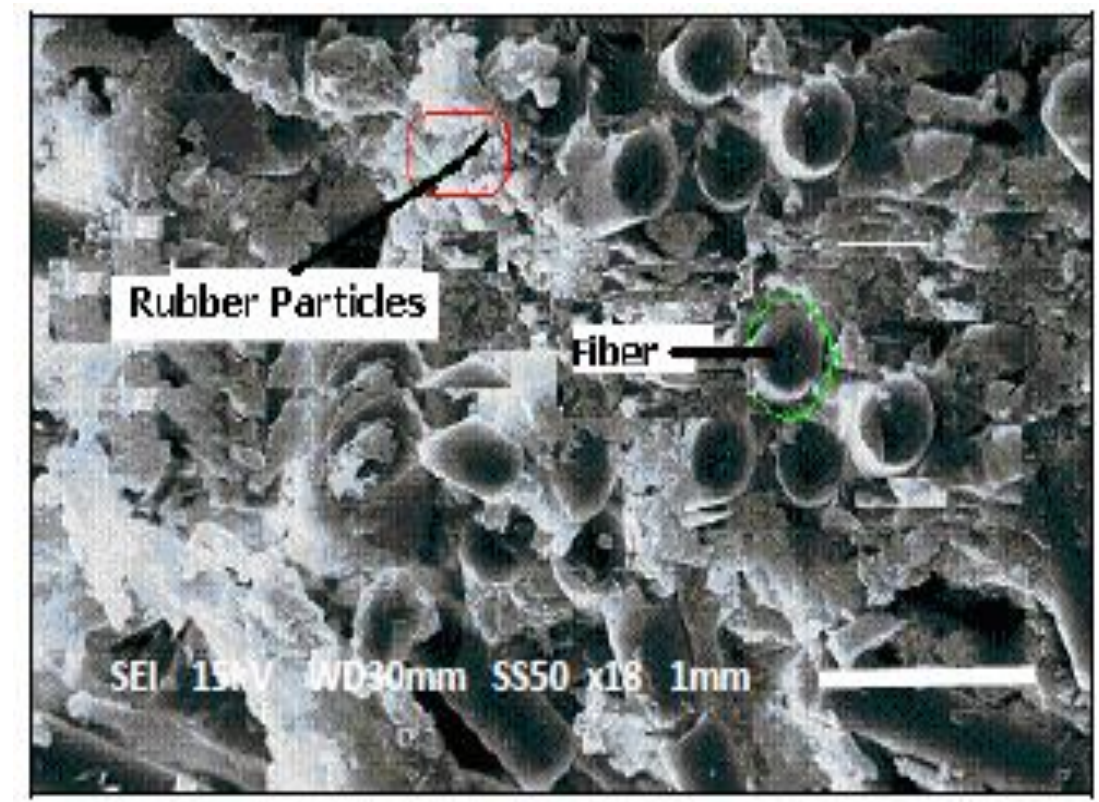

Figure 3. SEM micrograph of rubber-containing glass fabric epoxy composite.

\section{DMA Studies}

\section{i) Frequency Sweep}

Flexural loss factors (measure of damping) in the three-point bending of the glass epoxy composite with a frequency sweep in the range of $0-200 \mathrm{~Hz}$ at room temperature are 
reported in Figure 4. Tan $\delta$ in bending is increased with a frequency up to $110 \mathrm{~Hz}$ and then decreased for all the particle sizes considered. A similar trend is observed in the case of the loss factor in shear. DMA results reported in Figure 5 represent the variations in Tan $\delta$ in shear with frequency for all particle sizes. Tan $\delta$ increases with frequency up to $100 \mathrm{~Hz}$ and then decreases for all particle sizes considered. At lower frequencies, the energy dissipation is less and hence a lower Tan $\delta$ is reported. The damping is directly proportional to the square of the amplitude, and at higher frequencies the amplitudes are lower (Rao, 2004). Hence Tan $\delta$ in both bending and shear modes increase up to a certain frequency and then decrease. An increment in Tan $\delta$ is observed in both bending and shear with the addition of natural rubber particles in the epoxy glass fabric composite. The viscoelastic natural rubber particles present at the interphase (a third phase at the interface of the fibre and matrix due to chemical reactions), producing a micro slip and generate damping leading to an increase in Tan $\delta$. Experimental results revealed that the loss factor decreased with the size of the natural rubber particle inclusions in bending and shear except for the sizes $0.254 \mathrm{~mm}$ and $0.0975 \mathrm{~mm}$. A specific observation is that in both modes Tan $\delta$ is maximum for a particle size $0.254 \mathrm{~mm}$ among the selected particle sizes. For a fibre composite system, the total damping present in the system depends on the damping capacity of the fibres, matrix and interphase formed between matrix and fibre. The probability of the existence of smaller particles such as $0.0975 \mathrm{~mm}$ in the fibre matrix interphase is very low, and hence a lower damping is reported with $0.0975 \mathrm{~mm}$ compared with $0.254 \mathrm{~mm}$. Similarly at higher rubber particle sizes the energy dissipation due to micro-shear yield mode of deformation is suppressed and decreases the damping (Charles, 1996). Hence, 0.254 $\mathrm{mm}$ rubber particle inclusions improved the damping of the composite among the selected particle sizes.

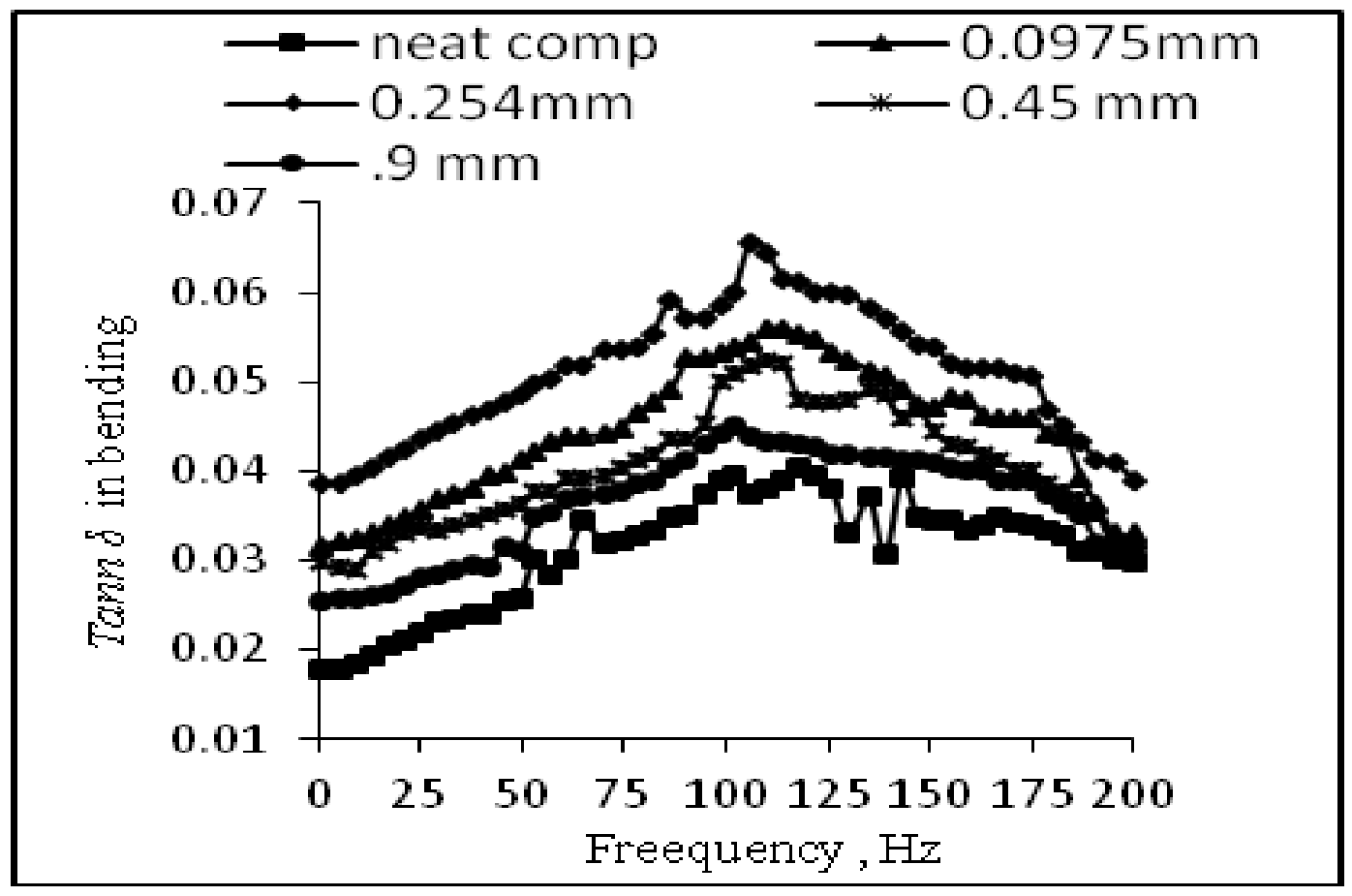

Figure 4. Variation in flexural loss factor in 3-point bending. 


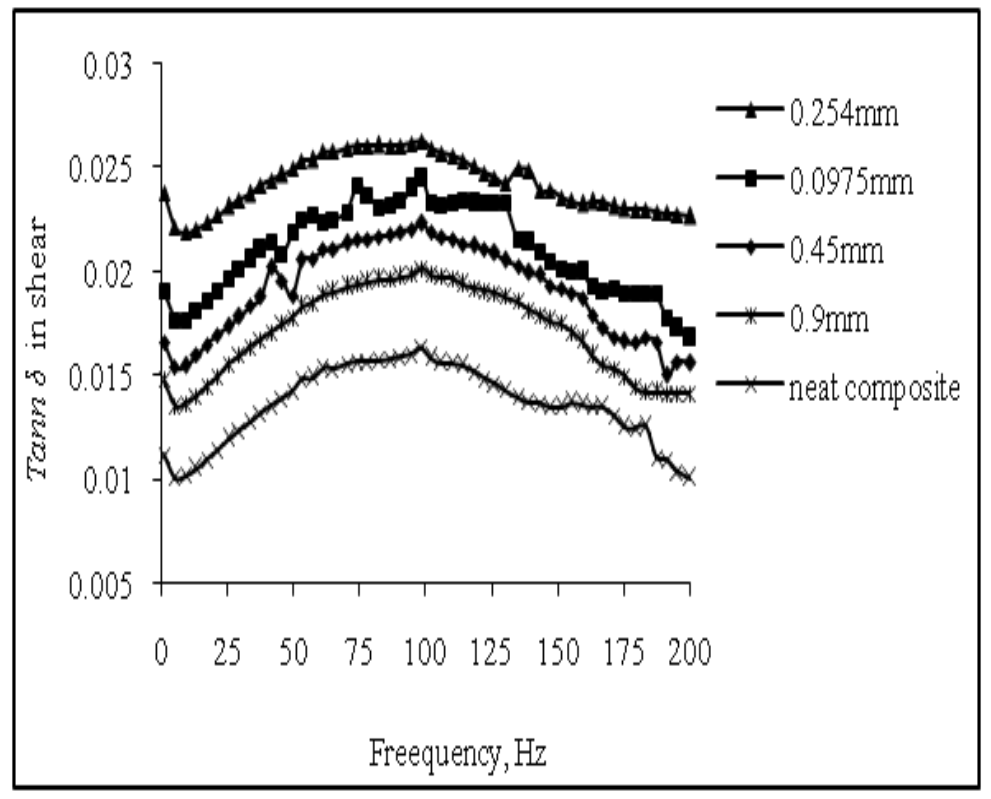

Figure 5. Variation in shear loss factor with frequency

Figure 6 shows the variation in E' in the flexural mode with frequency for all composite specimens. It is observed that the flexural storage modulus at all particle sizes is almost constant with frequency up to a range of $100 \mathrm{~Hz}$ to $110 \mathrm{~Hz}$, and then increases slightly. The rubber particle inclusions in the glass epoxy composite reduce the flexural E'. The micro-slip between the rubber particles at the interphase layers is attributed to be the reason for this reduction in stiffness (Cho et al., 2006; Ravi Sankar et al., 2010). The reduction in flexural E' increased with the size of the rubber particle inclusions. For smaller particle inclusions, i.e. $0.0975 \mathrm{~mm}$ and $0.254 \mathrm{~mm}$, the reduction is at about $10 \%$ to $15 \%$, whereas at particle sizes of $0.45 \mathrm{~mm}$ and $0.9 \mathrm{~mm}$ it is about $30 \%$ to $40 \%$. This is due to stress concentrations in larger particles due to abrupt changes in the material properties.

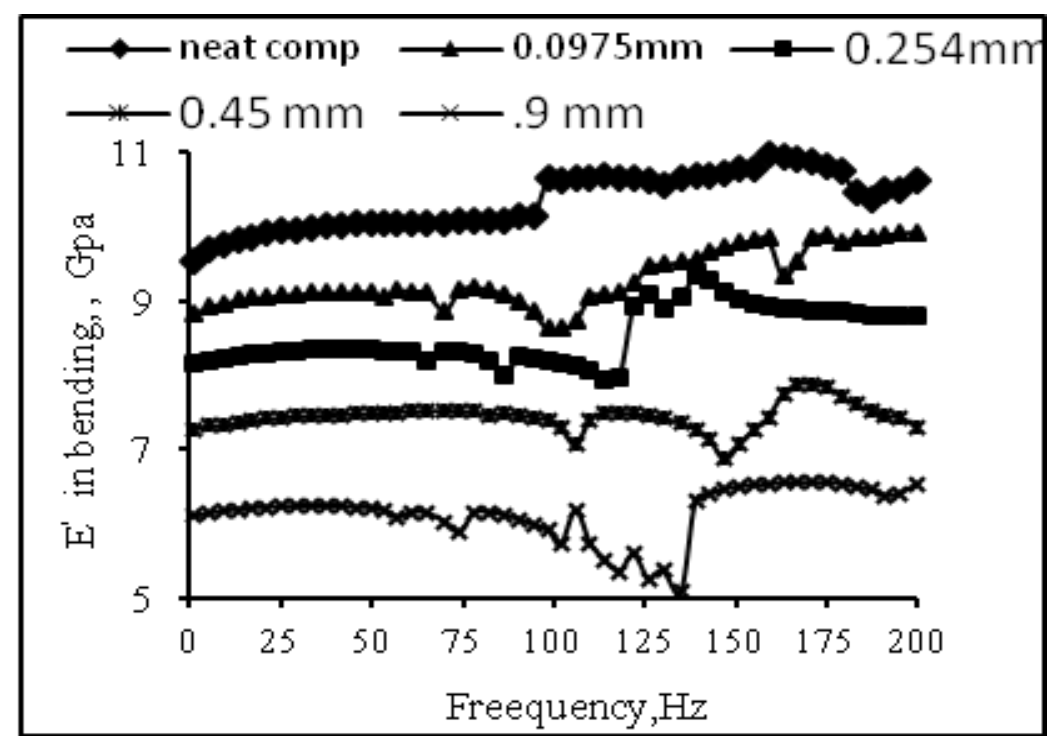

Figure 6.Variation in E' (bending) with frequency. 
The experimental values presented in Figure 7 explain the effect of particle size on $E^{\prime}$ in shear with frequency. The E' in shear mode is almost constant with the frequency considered. As in the case of three-point bending, the rubber particle inclusions reduce the shear E' at all frequencies. The shear E' is reduced by $10 \%$ to $20 \%$ to that of the pure composite, for all the sizes of rubber particle inclusions. Among the selected particle sizes, E' in shear is reduced with an increase in the size of the inclusions. This may be due to the stress-raising tendency of larger particle sizes (Cho et al., 2006; Ravi Sankar et al., 2010).

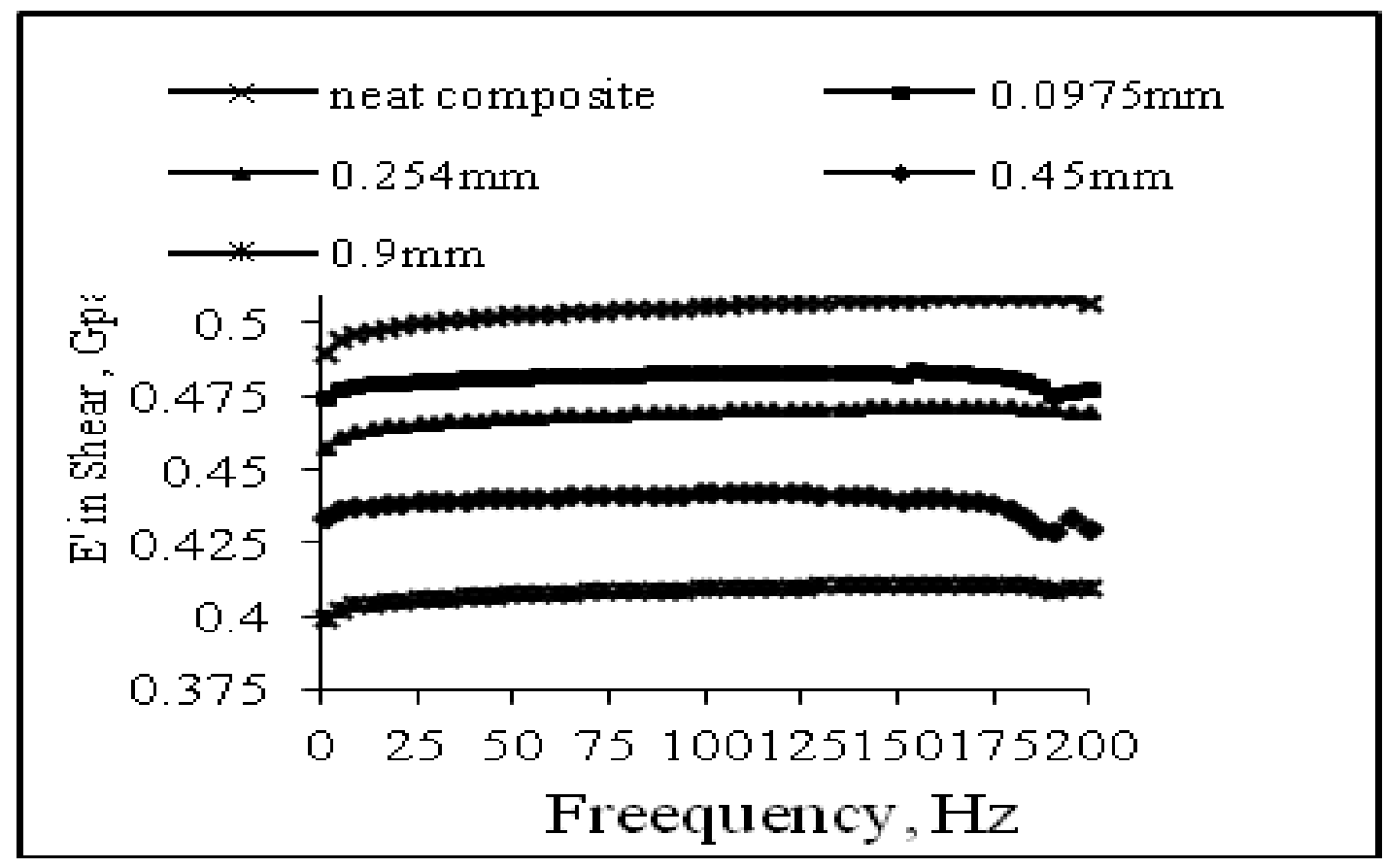

Figure 7. Variation in shear storage modulus with frequency

\section{ii) Temperature Sweep}

The effect of rubber particle size inclusions in the glass epoxy composite on loss factors in three-point bending with temperature at $10 \mathrm{~Hz}$ is reported in Figure 8. It is observed that the glass transition temperature $\mathrm{T}_{\mathrm{g}}$, is shifted to the lower side due to the addition of rubber inclusions because of the increased mobility of the rubber molecules at higher temperatures. $\mathrm{T}_{\mathrm{g}}$ for the neat composite is around $140^{\circ} \mathrm{C}$, whereas for the rubber-filled composites it is around $85^{\circ}$ to $90^{\circ} \mathrm{C}$. The size of particle inclusions on $\mathrm{T}_{\mathrm{g}}$ is insignificant. The peak magnitude of the loss factor is highest with a particle size of $0.254 \mathrm{~mm}$, as in the case of the frequency sweep. The magnitude of the peak is decreased with increase in particle size. At temperatures over $90^{\circ} \mathrm{C}$, the micro-slip at the interphase of the fibre, matrix and particle inclusions increased significantly and the mobility of polymer chains also increases at higher temperatures, thereby considerably increasing damping. The DMA results revealed (Figure 9) that E' in three-point bending at a constant frequency of $10 \mathrm{~Hz}$. E' slightly decreased with temperature for all composite specimens. The reduction in E' in three-point bending is drastic on passing through the $T_{g}$. On passing through $T_{g}$ the molecular relaxations of viscoelastic rubber particles and polymer chains take place and causes a reduction in the storage modulus. 


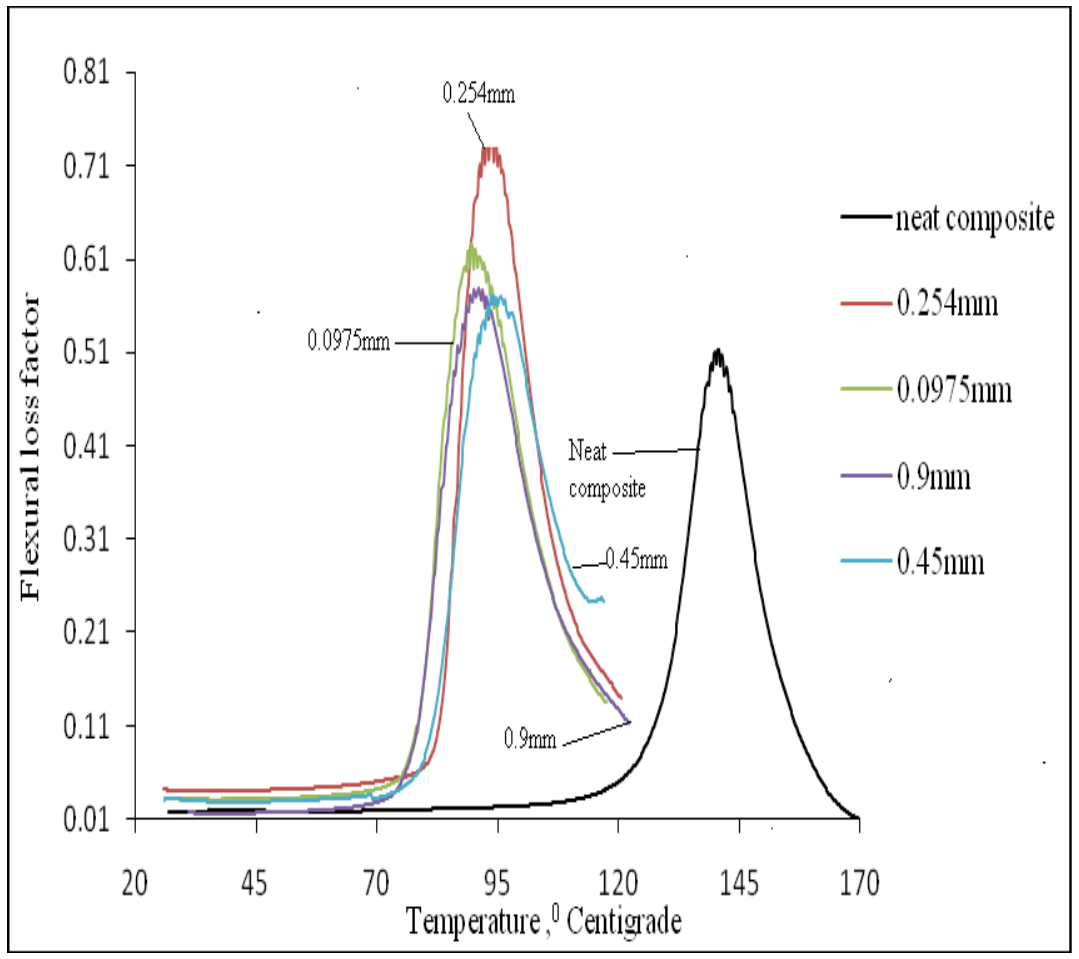

Figure 8. Variation in Tan $\delta$ (bending) with temperature

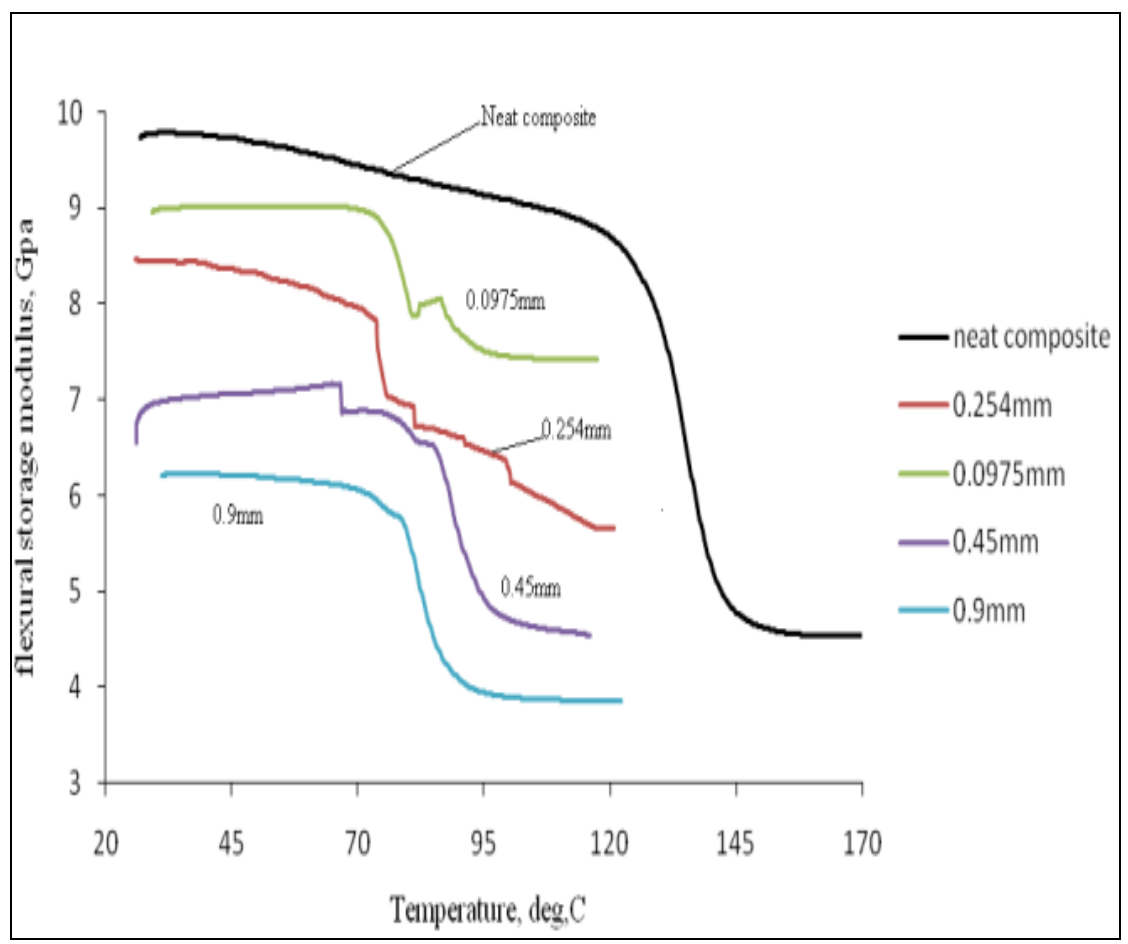

Figure 9. Variation in E' in bending with temperature.

\section{IMPLEMENTATION OF ANN}

The dynamic properties estimated are used for building two RBF models to predict the storage modulus and loss factor in two different scenarios: viz. in three-point bending 
and shear the in case of a frequency sweep, and in three-point bending at $10 \mathrm{~Hz}$ in the case of a temperature sweep. RBF networks have a static Gaussian function as the nonlinearity for the hidden layer processing elements (Bose and Liang, 1998).

Table1. Input and output parameters of ANN model.

\begin{tabular}{|c|c|c|c|}
\hline \multicolumn{4}{|c|}{ Input } \\
\hline \multicolumn{2}{|c|}{ Model I } & \multicolumn{2}{|l|}{ Model II } \\
\hline Frequencies $(\mathrm{Hz})$ & $1-200$ & Temperature $\left({ }^{\circ} \mathrm{C}\right)$ & Up to 200 \\
\hline Particle sizes $(\mathrm{mm})$ & $\begin{array}{l}0.09,0.254, \\
0.45,0.9\end{array}$ & $\begin{array}{l}\text { Particle sizes } \\
(\mathrm{mm})\end{array}$ & $\begin{array}{l}0.09, \quad 0.254, \\
0.45,0.9\end{array}$ \\
\hline \multicolumn{4}{|c|}{ Output (Model I and II) } \\
\hline Storage modulus & & In bending & \\
\hline Loss factor & & In bending & \\
\hline
\end{tabular}

Table. 2 Predicted and experimental values of dynamic properties at various frequencies

\begin{tabular}{|c|c|c|c|c|c|c|c|c|c|c|c|c|c|}
\hline \multirow{3}{*}{$\begin{array}{l}\text { Freq } \\
\mathrm{Hz}\end{array}$} & \multirow{3}{*}{$\begin{array}{l}\text { Size } \\
\mathrm{mm}\end{array}$} & \multirow{2}{*}{\multicolumn{2}{|c|}{$\begin{array}{c}\text { Experimental } \\
\text { Bending }\end{array}$}} & \multicolumn{4}{|c|}{ Predicted } & \multicolumn{6}{|c|}{ Percentage Error } \\
\hline & & & & \multicolumn{2}{|c|}{ Shear } & \multicolumn{2}{|c|}{ Bending } & \multicolumn{2}{|c|}{ Shear } & \multicolumn{2}{|c|}{ Bending } & \multicolumn{2}{|c|}{ Shear } \\
\hline & & $\begin{array}{c}\mathrm{E} \\
\mathrm{MPa}\end{array}$ & $\tan \delta$ & $\begin{array}{c}\mathrm{E} \\
\mathrm{MPa}\end{array}$ & $\ln \delta$ & $\begin{array}{c}\mathrm{E} \\
\mathrm{MPa}\end{array}$ & $\tan \delta$ & $\begin{array}{c}\mathrm{E} \\
\mathrm{MPa}\end{array}$ & $\ln \delta$ & $\mathrm{E}^{\prime}$ & $\tan \delta$ & $\mathrm{E}^{\prime}$ & $\tan \delta$ \\
\hline 13.2 & 0.098 & 9009 & 0.0331 & 478.6 & 0.0181 & 8893 & 0.03425 & 476.32 & 0.019 & 1.2909 & -3.415 & 0.4764 & -3.34 \\
\hline 17.2 & 0.098 & 9038 & 0.034 & 479.1 & 0.0186 & 8921 & 0.03515 & 476.83 & 0.019 & 1.2956 & -3.431 & 0.4738 & -3.13 \\
\hline 21.2 & 0.098 & 9060 & 0.0349 & 479.5 & 0.0191 & 8942 & 0.0361 & 477.27 & 0.02 & 1.2991 & -3.394 & 0.4651 & -2.93 \\
\hline 25.4 & 0.098 & 9078 & 0.0358 & 479.9 & 0.0196 & 8960 & 0.03697 & 477.68 & 0.02 & 1.302 & -3.418 & 0.4626 & -2.76 \\
\hline 45.6 & 0.098 & 9128 & 0.0397 & 481.1 & 0.0209 & 9008 & 0.04095 & 478.96 & 0.021 & 1.3179 & -3.115 & 0.4448 & -2.83 \\
\hline 29.4 & 0.254 & 8329 & 0.0446 & 466 & 0.0235 & 8392 & 0.04284 & 466.58 & 0.023 & -0.75 & 3.9632 & -0.1245 & 3.399 \\
\hline 33.5 & 0.254 & 8340 & 0.0455 & 466.4 & 0.0238 & 8402 & 0.04369 & 466.94 & 0.023 & -0.741 & 3.9692 & -0.1158 & 3.221 \\
\hline 37.6 & 0.254 & 8346 & 0.0463 & 466.7 & 0.0242 & 8409 & 0.04445 & 467.23 & 0.023 & -0.756 & 3.9957 & -0.1136 & 3.125 \\
\hline 41.6 & 0.254 & 8349 & 0.0469 & 467 & 0.0244 & 8410 & 0.04515 & 467.51 & 0.024 & -0.732 & 3.635 & -0.1092 & 2.734 \\
\hline 21.2 & 0.45 & 7410 & 0.0331 & 438.4 & 0.017 & 7468 & 0.03371 & 440.15 & 0.017 & -0.788 & -1.868 & -0.3992 & -2.21 \\
\hline 25.4 & 0.45 & 7428 & 0.0338 & 438.8 & 0.0174 & 7486 & 0.0344 & 440.55 & 0.018 & -0.784 & -1.914 & -0.3988 & -2.16 \\
\hline 29.4 & 0.45 & 7444 & 0.0335 & 439.1 & 0.0179 & 7502 & 0.03419 & 440.86 & 0.018 & -0.779 & -2.173 & -0.4008 & -2.05 \\
\hline 33.5 & 0.45 & 7447 & 0.0339 & 439.3 & 0.0184 & 7506 & 0.03467 & 441.07 & 0.019 & -0.786 & -2.229 & -0.4029 & -1.92 \\
\hline 102 & 0.45 & 7290 & 0.051 & 441.5 & 0.0219 & 7348 & 0.05155 & 443.37 & 0.022 & -0.789 & -1.174 & -0.4236 & -1.19 \\
\hline 98.5 & 0.9 & 5908 & 0.0441 & 409.3 & 0.0243 & 5908 & 0.04407 & 409.3 & 0.024 & 0 & 0 & 0 & 0 \\
\hline
\end{tabular}

An exact fit model of RBF is chosen with a spread constant of 0.5. Among the available experimental data of around 400 data points in the case of the frequency model and 2000 data points in the case of temperature model (more data points are taken for the temperature model as the observations are highly non-linear), 50 data points are kept aside for testing purposes, while the rest of the data points are used for training the network. The network was implemented using MATLAB 7®. For the present study, frequencies and particle sizes are selected as input variables and E', Tan $\delta$ in bending and shear are chosen as the output parameters. The same network is also used separately to predict the loss factors and storage modulus in bending at a given temperature and particle size within the range considered at $10 \mathrm{~Hz}$. The input and output 
parameters are presented in Table 1. ANN simulation (testing) results for different frequencies and different temperatures are shown in Tables 2 and 3 respectively. It can be seen that the predicted values are very close to the experimental values, in fact in some cases they are the same. Percentage errors obtained are less than $5 \%$ in all cases, thus validating the models.

Table. 3. Predicted and experimental values of dynamic properties in bending at various temperatures.

\begin{tabular}{|c|c|c|c|c|c|c|c|}
\hline \multirow[b]{2}{*}{$\begin{array}{c}\text { Temp. } \\
\left({ }^{\circ} \mathrm{C}\right)\end{array}$} & \multirow[b]{2}{*}{$\begin{array}{l}\text { Size } \\
(\mathrm{mm})\end{array}$} & \multicolumn{2}{|c|}{ Experimental } & \multicolumn{2}{|c|}{ Predicted } & \multicolumn{2}{|c|}{ Percentage Erro1 } \\
\hline & & $\begin{array}{c}\text { Modulus } \\
(\mathrm{MPa})\end{array}$ & $\tan \delta$ & $\begin{array}{c}\text { Modulus } \\
\text { (MPa) }\end{array}$ & $\tan \delta$ & $\begin{array}{c}\text { Modulus } \\
\text { (MPa) }\end{array}$ & $\tan \delta$ \\
\hline 29.65 & 0.0975 & 8969 & 0.0321 & 8917 & 0.03295 & 0.5798 & -2.783 \\
\hline 59.1 & 0.0975 & 9018 & 0.0353 & 8896.7 & 0.03664 & 1.3451 & -3.875 \\
\hline 37.97 & 0.254 & 8436 & 0.0408 & 8467.9 & 0.0389 & -0.378 & 4.76 \\
\hline 114.4 & 0.254 & 6537 & 0.1854 & 6444.3 & 0.18256 & 1.4181 & 1.5318 \\
\hline 39.7 & 0.45 & 7398 & 0.0292 & 7458.6 & 0.02989 & -0.819 & -2.314 \\
\hline 76.33 & 0.45 & 7497 & 0.0435 & 7480.3 & 0.04511 & 0.2228 & -3.68 \\
\hline 96.73 & 0.45 & 5475.3 & 0.5667 & 5508.7 & 0.5727 & -0.61 & -1.061 \\
\hline 40.42 & 0.9 & 6226 & 0.0167 & 6226 & 0.01676 & 0 & -0.119 \\
\hline 96.01 & 0.9 & 3932 & 0.4984 & 3929.1 & 0.4914 & 0.0738 & 1.4045 \\
\hline 122 & 0.9 & 3857.62 & 0.115 & 3857.5 & 0.11362 & 0.0031 & 1.2 \\
\hline
\end{tabular}

\section{CONCLUSIONS}

The dynamic properties of particle rubber-containing composites are estimated using DMA. ANN-based prediction models to predict the dynamic properties of these composites are developed using RBF. Based on the results obtained the following conclusions may be drawn.

i) Inclusion of rubber particles is found to increase the loss factors in both bending and shear, whereas the storage modulus decreases. The loss factors in bending and shear decreased with the size of the natural rubber particle inclusions except for sizes of $0.254 \mathrm{~mm}$ and $0.0975 \mathrm{~mm}$. A specific observation is that both loss factors are maximum with a particle size of $0.254 \mathrm{~mm}$ among the selected particle sizes.

ii) At smaller particle inclusions, i.e. $0.0975 \mathrm{~mm}$ and $0.254 \mathrm{~mm}$, there is a reduction in E' of about $10 \%$ to $15 \%$, whereas at particle sizes of $0.45 \mathrm{~mm}$ and $0.9 \mathrm{~mm}$ it is about $30 \%$ to $40 \%$. At smaller particle sizes a considerable improvement in Tan $\delta$ a with lower reduction in stiffness is observed in both bending and shear modes at all frequencies considered.

iii) A shift in $\mathrm{T}_{\mathrm{g}}$ is observed with the inclusion of rubber particles. The size of the particles has no significant effect on the glass transition temperature.

iv) ANN models are found to be accurate and able to predict Tan $\delta$ and E' for both frequencies and temperatures. 


\section{ACKNOWLEDGEMENTS}

The author thanks GITAM University, India for providing research funding to carry out the work.

\section{REFERENCES}

Adebisi, A.A., Maleque, M.A. and Rahman, M.M. 2011. Metal matrix composite brake rotor: historical development and product life cycle analysis. International Journal of Automotive and Mechanical Engineering, 4: 471-480.

Al-Assaf, Y. and EI Kadi, H. 2001. Fatigue life prediction of unidirectional glass fiber/epoxy composite laminae using neural networks. Composite Structures, 53: 65-71.

Arends, C.B. 1996. Polymer toughening. New York: Marcel Dekker.

ASTM D2584-08. 2008. Standard test method for ignition loss of cured reinforced resins Plastics I, 08.01.

Aymerich, F. and Serra, M. 1998. Prediction of fatigue strength of composite laminated by means of neural networks. Key Engineering Materials, 144: 231-240.

Bachtiar, D., Sapuan, S.M. and Hamdan, M.M. 2010. Flexural properties of alkaline treated sugar palm fibre reinforced epoxy composites. International Journal of Automotive and Mechanical Engineering, 1: 79-90.

Bhaskar, H.B. and Sharief, A. 2012. Effect of solutionizing on dry sliding wear of A12024-Beryl metal matrix composite. Journal of Mechanical Engineering and Sciences, 3: 281-290.

Bose, N.K. and Liang, P. 1998. Neural networks fundamentals with graphs, algorithms and applications. India: Tata McGraw Hill.

Cho, J., Joshi, M.S. and Sun, C. 2006. Effect of inclusions size on mechanical properties of polymeric composites with micro and nano particles. Composite Science and Technology, 66: 1941-1952.

Collyer, A.A. 1994. Rubber toughened engineering plastics. First edition. UK: Chapman and Hall.

Crandall, S.H. 1970. The role of damping in vibration theory. Journal of Sound and Vibration, 11(1): 3-18.

Ferreira, A.J.M. and Fasshauer, G.E. 2007. Analysis of natural frequencies of composite plates by an RBF-pseudospectral method. Composite Structures, 79(2): 202-210.

Finegan, I.C. and Gibson, R.F. 1997. Analytical and experimental characterization of damping and stiffness in polymer composites having coated fibers as reinforcement. Proc. ASME Noise Control and Acoustics Division (NCA), vol. 24. American Society for Mechanical Engineers, pp. I27-138.

Hardinnawirda, K. and Aisha, S.R.I. 2012. Effect of rice husks as filler in polymer matrix composites. Journal of Mechanical Engineering and Sciences, 2: 181186.

Hong, Z., Bo, L., Guangsu, H. and Jia, H. 2004. A novel composite sound absorber with recyclic rubber particles. Journal of Sound and Vibration, 304: 400-406.

Ibrahim, M.S., Sapuan, S.M. and Faieza, A.A. 2012. Mechanical and thermal properties of composites from unsaturated polyester filled with oil palm ash. Journal of Mechanical Engineering and Sciences, 2: 133-147.

Jeffrey, K.J.T., Tarlochan, F. and Rahman, M.M. 2011. Residual strength of chop strand mats glass fiber/epoxy composite structures: effect of temperature and water 
absorption. International Journal of Automotive and Mechanical Engineering, 4: 504-519.

Jiang, Z., Gyurova, L., Zhang, Z., Friedrich, K. and Schlar, A.K. 2008. Neural network based prediction on mechanical and wear properties of short fibers reinforced polyamide composites. Materials and Design, 29: 628-637.

Lee, J.A., Almond, D.P. and Harris, B. 1999. The use of neural networks for the prediction of fatigue lives of composite materials. Composites Part A: Applied Science and Manufacturing, 30: 1159-1169.

Mantena, P.R., Gibson, R.F. and Hawng, S.J. 1991. Optimal constraint viscoelastic tape lengths for maximizing damping in laminated composites. AIAA Journal, 29: 1678-1685.

Mathur, S., Gope, P.C. and Sharma, J.K. 2007. Prediction of fatigue lives of composites material by artificial neural network. Proceedings of the SEM 2007 Annual Conference and Exposition, Springfield, Massachusetts, USA, June 4-6, Paper 260.

Pidaparti, R.M.V. and Palakal, M.J. 1993. Material model for composites using neural networks. AIAA Journal, 31(8): 1533-1535.

Rao, S.S. 2004. Mechanical vibrations. 4th edition. Singapore: Pearson Education.

Ravi Sankar, H., Vamsi Krishna, P., Bhujanga Rao, V. and Bangaru Babu, P. 2010. The effect of natural rubber particle inclusions on the mechanical and damping properties of epoxy-filled glass fibre composites. Journal of Materials: Design and Applications, 224: 63-70.

Rotz, C.A. and Barrett, D.J. 1991. Co-cured damping layers in composite structures. In: Proceedings of the 23rd International SAMPE Technical Conference, Covina, CA, Society for the Advancement of Materials and Process Engineering, pp. 352-363.

Saadatmanesh, H., Ehsani, M.R. and Li, M.W. 1994. Fiber composites for new and existing structures. ACI Structural Journal, 91(3): 346-354.

Sapuan, S.M. and Mujtaba, I.M. 2010. Composite materials technology - neural network applications. New York: CRC Press, Taylor \& Francis Group.

Singh, U.P., Biswas, B.K. and Ray, B.C. 2009. Evaluation of mechanical properties of polypropylene filled with wollastonite and silicon rubber. Materials Science and Engineering A, 501: 94-98.

Tjong, S.C., Aixes, S., Who, R.K. and Mai, Y.W. 2002. Mechanical behavior and fracture toughness evaluation of maleic anhydride compatibilized short glass fiber/SEBS/polypropylene hybrid composites. Composites Science and Technology, 62(6): 831-840.

Trindade, M.A. and Benjeddou, A. 2002. Hybrid active-passive damping treatments using viscoelastic and piezoelectric materials: review and assessment. Journal of Vibration and Control, 8(6): 699-745.

Umar, A.H., Zainudin, E.S. and Sapuan, S.M. 2012. Effect of accelerated weathering on tensile properties of kenaf reinforced high-density polyethylene composites. Journal of Mechanical Engineering and Sciences, 2: 198-205.

Zhang, Z. and Friedrich, K. 2003. Artificial neural networks applied to polymer composites: a review. Composites Science and Technology, 63: 2029-2044.

Zhu, P., Zhou, S., Zhen, J. and Li, Y. 2010. Application of artificial neural network in composite research. Advances in Swarm Intelligence Lecture, Notes in Computer Science, 6146: 558-563. 